\section{Consent for children participating in research}

To the Editor: With reference to the article and more recent letter on the implications for researchers, service providers and policy makers of child consent in South African law, ${ }^{1,2}$ I wish to put forward a different but more appropriate approach to consent for children participating in research. Although I agree that s71 of the National Health Act of $2003^{3}$ is not in force, the Guidelines of the National Health Research Ethics Committee are. ${ }^{4}$ The NHREC is quite clear when it comes to consent for children participating in research. Research should be of minimal risk and consent for minors must be obtained from the parents or legal guardian in all but exceptional circumstances (such as emergencies), as well from as the minor where $s /$ he is competent to make the decision. This is consistent with international practice, and I urge all researchers and Human Research Ethics Committees to be compliant with this guideline in the meantime.

\section{Shan Naidoo}

Department of Community Health and

Health Research Ethics Committee (Medical), Faculty of Health Sciences

University of the Witwatersrand

Johannesburg

shan.naidoo@wits.ac.za

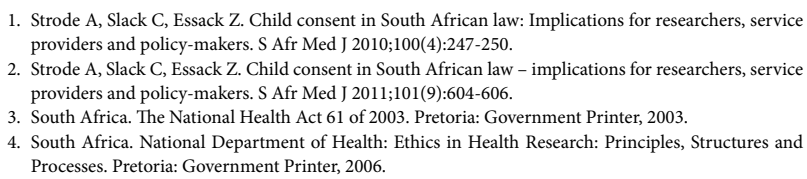

Slack, Strode and Essack reply: Professor Naidoo argues that an 'appropriate approach' to child research is that the 'research should be of minimal risk and consent for minors must be obtained from the parent or legal guardian in all but exceptional instances' and, moreover, that this is consistent with South African national ethical guidelines and international practice.

On the contrary, it is not clear why this proposal is appropriate in all instances, and our South African ethical-legal framework does not provide unqualified support for such a position.

Current South African ethical guidelines, including the Good Practice guidelines ${ }^{1}$ and the general ethical guidelines Structures, Principles and Processes, ${ }^{2}$ provide that in certain circumstances children are permitted to be enrolled in research that presents more than minimal risk. Where the research procedures hold out the prospect of direct benefit, there is no express cap on the risk level, although the risks must be reasonable in relation to the anticipated benefit (and appropriately minimised); and where the research procedures do not hold out the prospect of direct benefit, the risks must represent a minor increase over minimal risk. ${ }^{3}$ This position is echoed in international frameworks, such as the Code of Federal Regulations in the USA. ${ }^{4}$ Should children's participation in research be limited exclusively to minimal-risk research, it is difficult to see how children would ever be enrolled in clinical trials of experimental products.

Furthermore, in current South African ethical guidelines child participation in research is sometimes permissible even when parental or guardianship consent is not obtained, for example Structures, Principles and Processes ${ }^{2}$ (correctly) allow older adolescents to participate in minimal-risk research with independent consent. The Good Practice guidelines ${ }^{1}$ also recognise the ability of caregivers providing long-term day-to-day care of children to provide proxy consent in some instances. International frameworks also allow for waivers of parental consent in certain specific instances, and where sufficient safeguards are in place.

We do not dispute that in all instances of child research, research ethics committees must make complex determinations about whether the research presents acceptable risks to child participants; nor that in many instances of child research, proxy consent by an adult is most desirable and that in many instances proxy consent should be obtained from a parent/legal guardian. ${ }^{5}$ However, we argue here that the situation is not as simple as the proposal set out by Professor Naidoo, and that any competent ethico-legal framework should be able to accommodate a broad range of health research proposals involving children.

Acknowledgements. The work of the HIV/AIDS Vaccines Ethics Group is funded by the South African AIDS Vaccine Initiative (SAAVI). The views expressed in this letter do not necessarily reflect those of SAAVI.

1. Department of Health. Guidelines for Good Practice in the Conduct of Clinical Trials with Human Participants in South Africa [Internet]. 2006. http://www.doh.gov.za/docs/index.html (accessed 5 March 2008).

2. Department of Health. Ethics in Health Research: Principles, Structures and Processes. Pretoria: DOH, 2004.

Slack, C. Why we don't need a relative risk standard for adolescent HIV vaccine trials in South Africa. Open Peer Commentary. Am J Bioeth 2011;11(6):1-2.

US Department of Health and Human Services. Code of Federal Regulations: Protection of human . _11/21cfr50_11.html

A provide proxy consent to child research in South Africa. South African Journal of Bioethics and Law 2011;3(2):55-58.

\section{Mini-slings - concern regarding marketing of these devices in South Africa}

To the Editor: Aggressive marketing of medical devices impacts on the day-to-day practice of clinicians. The marketing of the mini-sling devices for stress urinary incontinence (SUI) in women is an area of major concern to us. SUI is the involuntary leakage of urine from the urethra with exertion, or on sneezing or coughing, and affects up to $35 \%$ of women. ${ }^{1}$ It is a distressing condition and significantly impacts on quality of life.

Traditional interventions include pelvic floor exercises and open retropubic colposuspension. Ulmsten in 1995 introduced an effective minimally invasive option for surgically managing SUI, the 'tensionfree vaginal tape' (TVT) (Gynecare, Ethicon, Somerville, USA). ${ }^{2}$ This was followed by development of the transoburator-type sling, which avoided the risks of bladder, bowel and major vascular injury. ${ }^{3}$ Both slings are made of synthetic mesh and are placed mid-urethrally, and their placement is the most commonly performed surgical procedure for SUI.

Long-term follow-up of Ulmsten's original series found an objective cure rate of $90 \%$ at 10 years. Level 1 evidence found efficacy to be equivalent to that of colposuspension. Meta-analysis has further shown equivalence in terms of cure between the trans-obturator and retropubic placement of mid-urethral slings. ${ }^{4}$

Mid-urethral slings therefore offer a highly efficacious minimally invasive surgical option with low postoperative morbidity. Device manufacturers have in the past 5 years introduced and strongly promoted eight further so-called 'mini-slings' that are claimed to be less invasive, and are placed via a small single vaginal incision.

There is little quality evidence to support the use of mini-slings. Nearly all the available studies show inferior efficacy. The most studied device, the TVT-Secure, was the subject of a 12-month outcome study 
that reported an objective cure rate of $76 \%$, considerably lower than the $90 \%$ reported long-term cure rate for the standard TVT. ${ }^{5}$ The other widely marketed device, the Mini-Arc, also has inconsistent outcomes with some studies showing cure rates as low as $62 \%{ }^{6}$

Gynaecologists and urologists need to be aware of these poorer outcomes, for the TVT-Secur and the Mini-Arc in particular. While mini-slings hold future promise, present products are inferior to standard sling operations and their use should be discouraged.

\author{
John Lazarus \\ Division of Urology \\ Groote Schuur Hospital and University of Cape Town \\ j.lazarus@uct.ac.za
}

\section{Stephen Jeffery}

Department of Obstetrics and Gynaecology

Groote Schuur Hospital and University of Cape Town

\section{Lisa Kaestner}

Division of Urology

Groote Schuur Hospital and University of Cape Town

\footnotetext{
1. Luber KM. The definition, prevalence, and risk factors for stress urinary incontinence. Rev Urol 2004;6(suppl 3):S3-S9.

2. Ulmsten U, Petros P. Intravaginal slingplasty (IVS): an ambulatory surgical procedure for treatment of

female urinary incontinence. Scand J Urol Nephrol 1995;29:75-82. 3. Delorme E. [Transobturator urethral suspension: mini-invasive p
urinary incontinence in women]. Prog Urol 2001;11(6):1306-1313.

4. Fong EDM, Nitti VW. Mid-urethral synthetic slings for female stress urinary incontinence. BJU Int Fong EDM, Nitti

2010;106:596-608.
5. Walsh CA. TVT-Secur mini-sling for stress urinary incontinence: a review of outcomes at 12 months. 5. Walsh CA. TVT-Secur mini-s
BJU Int 2011;108(5):652-627.

6. Deole N, Kaufmann A, Arunkalaivanan A. Evaluation of safety and efficacy of single-incision midurethral short tape procedure (MiniArc ${ }^{\text {"I }}$ tape) for stress urinary incontinence under local anaesthesia. Int Urogynecol J 2011;22(3):335-339.
}

\section{Management guidelines for common kidney disorders relevant to South Africa}

To the Editor: World Kidney Day (WKD), an annual event, is celebrated on 8 March 2012. As a project for WKD, the National Kidney Foundation of South Africa (NKFSA) has arranged for a group of experienced senior nephrologists from around the country to contribute to a guideline booklet presenting the diagnosis and state-of-the-art management of renal disorders. Its main aim is to educate and update general practitioners, but it should also be useful for under- and postgraduate students, urologists and specialist physicians.

The guideline is being edited and will be sent to the South African Renal Society for their endorsement. We aim to publish the guideline as a supplement to the South African Medical Journal. We thank the contributors to and supporters of the project, and the National Lotteries Distribution Trust Fund for financial support towards the initial draft copy of the guideline.

\section{A M Meyers}

Chairman, National Kidney Foundation of South Africa

\section{Fanie du Toit}

Administrator, NKFSA

$n k f s a @ m w e b . c o . z a$

\section{Health professionals should be speaking out about the victimisation of doctors in Bahrain}

To the Editor: Doctors in Bahrain who treated people wounded during and after demonstrations have been arrested, tried by a military court and given sentences of up to 15 years' imprisonment. A report by the Physicians for Human Rights ${ }^{1}$ recounts the result of an on-the-spot inquiry as follows: 'Our investigators spoke to eyewitnesses of abducted physicians, some of whom were ripped from their homes in the middle of the night by masked security forces ... [the report] documents other violations of medical neutrality, including the beating, abuse and threatening of Shia physicians at Salmaniya Hospital; government security forces stealing ambulances and posing as medics; the militarisation of hospitals and clinics, thus obstructing medical care; and rampant fear that prevents patients from seeking urgent medical treatment.' Most of the doctors are women, and there have been reports of torture, including electrocution and threats of rape while in detention. ${ }^{2}$

These accounts are shocking and remind South Africans of a sorry history where human rights abuses at the hands of security forces were allowed to go unchecked and where the health sector was drawn willingly and unwillingly into violations of the rights of patients and professionals. ${ }^{3}$ Not surprisingly, there has been sustained outcry from the medical profession in other parts of the world..$^{4-7}$ Following the exposé by Physicians for Human Rights, and pressure by the World Health Organization and the World Medical Association, it was announced by a civilian court that some charges against 20 health professionals would be dropped and that a new trial would begin to assess the allegations. ${ }^{8}$

We ask why there has been so little outcry in South Africa, a country whose history should make it acutely aware of the consequences of the political abuse of doctors. The South African Medical Association released a Medigram reporting the resolution of the WMA, ${ }^{9}$ but has not taken any proactive steps to champion the cause of the persecuted doctors. Why has SAMA not been more active? Why have members of the medical profession not seen it as their ethical obligation to take action in solidarity with colleagues, if only to press our government, a member of the UN Security Council, to take diplomatic action? One of the consistent findings of research into complicity of health professionals in human rights abuses ${ }^{3,10,11}$ has been the effect of isolation and a failure to stand up for colleagues under threat, a finding echoed in the conclusions of the Truth and Reconciliation Commission., ${ }^{3,11}$

It appears that since the late 1970s we have not learnt sufficiently the importance of health professionals speaking truth to power. One of us (SS) wrote to the President of SAMA, urging SAMA to take action, to which there was not even an acknowledgement. South Africans deserve better.

\section{Stuart Saunders \\ Emeritus Professor}

University of Cape Town

\section{Leslie London}

School of Public Health and Family Medicine

University of Cape Town

leslie.london@uct.ac.za 1. Physicians for Human Rights. Do no harm: A call for Bahrain to end systematic attacks on doctors
and patients. Physicians for Human Rights, Cambridge. April 2011. https://s3.amazonaws.com/PHR.../ bahrain-22April 4-45pm.pdf (accessed 12 January 2012). 
2. Sky News. Bahrain docs face jail despite torture claims. 22 November 2011. http://news.sky.com/ home/world-news/article/16115007 (accessed 17 January 2012).

3. Baldwin-Ragaven L, de Gruchy J, London L. An Ambulance of the Wrong Colour. Health Professionals, Human Rights and Ethics in South Africa. Cape Town: UCT Press, 1999.

4. Gray B, Ockelford P. Bahrain health workers in danger: call to action. N Z Med J 2011;124:109-110. 4. Gray B, Ockelford P. Bahrain health workers in danger: call to action. N Z Med J 2011;
5. Devi S. Medical community urged to defend Bahraini doctors. Lancet 2011;378:1287.

5. Devi S. Medical community urged to defend Bahraini doctors. Lancet 2011;378:1287.
6. Jackson G. Stop: the medical and human rights scandal in Bahrain. Int J Clin Pract 2011;65:823.

7. Friedrich MJ. Human rights report details violence against health care workers in Bahrain. JAMA 2011;306:475-476.

8. Nathanson V, Chrispin E. Bahraini health workers to be retried before a civilian court. BM 2011;343:d6547.

9. South African Medical Association. SAMA insists on a fair trial for Bahrain physicians. Press release 17 October 2012. http://www.samedicalorg/newsroom/media-releases/archived-mediareleases/17-october-2011.html?searched=Bahrain\&advsearch=oneword\&highlight=ajaxSearch highlight+ajaxSearch_highlightl (accessed 12 January 2012).

10. British Medical Association. The Medical Profession and Human Rights. Handbook for a Changing Agenda. London: Zed Press, 2001.

11. Rubenstein LS, London L, Baldwin-Ragaven L, and the Dual Loyalty Working Group. Dual Loyalty and Human Rights in Health Professional Practice. Proposed Guidelines and Institutional Mechanisms. A project of the International Dual Loyalty Working Group. Physicians for Human Rights and University project of the International Dual Loyalty Working Group. Physicians for Human Rights and University
of Cape Town, Boston, 2002. https://s3.amazonaws.com/PHR_Reports/dualloyalties-2002-report.pdf

\section{Side-effect of acetazolamide in prevention of acute mountain sickness}

To the Editor: The scientific letter by Firth et al. ${ }^{1}$ about the sideeffect of acetazolamide on a hiker on Mt Kilimanjaro makes a rather hasty conclusion about the recommendation of acetazolamide to prevent acute mountain sickness (AMS), especially in a rapid ascent climb such as Kilimanjaro. It is difficult to disagree about the pathophysiology of acetazolamide causing corneal oedema, but we must note that it is a drug used for glaucoma treatment, ${ }^{2}$ and the dosage regimen is usually higher than that prescribed for the prevention of AMS. Interestingly, the authors did not mention the dose and duration of acetazolamide in the article. The cause-effect relationship is difficult to establish from this case report without knowing the dosage regimen and control. Based on the rare sideeffect (if indeed it is) in this report, it would not be justifiable to advise against using acetazolamide as a prophylactic of AMS; this could rather invite other serious acute altitude illnesses that would be far more probable were it not used. Major trials with large numbers of participants have reported a fairly safe outcome of acetazolamide. ${ }^{3}$ Hence, we should continue using acetazolamide with caution for preventing AMS where there is rapid ascent profile.

\section{Matiram Pun}

Specialization Program in Mountain Medicine and High Altitude Physiology

Department of Medical Sciences

Faculty of Medicine

University of Calgary

Calgary, Canada

mpun@ucalgary.co
1. Firth PG, Gray C, Novis CA. High-altitude corneal oedema associated with acetazolamide. S Afr Med J 2011:101: 462 .

2. Lam PM. Glaucoma pharmacotherapy: implications for flying fitness. Aviat Space Environ Med 2005;76(8):786-793.

3. Gertsch JH, Basnyat B, Johnson EW, Onopa J, Holck PS. Randomised, double blind, placebo controlled comparison of ginkgo biloba and acetazolamide for prevention of acute mountain sickness among Himalayan trekkers: the prevention of high altitude sickness trial (PHAIT) BMJ 2002;328(7443):797.

Firth, Gray and Novis reply: We thank Dr Pun for his comments. The climber did not remember the dose she took, but thinks it was $250 \mathrm{mg}$ daily by mouth, starting on the ascent. While painful druginduced myopia with low doses of sulphonamides is a rare but welldescribed complication, this appears to involve different mechanisms to impairment of corneal endothelial function. ${ }^{1}$ Although we pointed out that a causal pathophysiology was not demonstrated, ${ }^{2}$ we therefore speculate that the interaction of drug effect with rapid ascent played a role.

Irrespective of the pathophysiology, it is prudent to discontinue a drug if adverse side-effects occur after dosing. Similarly, if symptoms occur following rapid ascent, it is sensible to remove the possible cause by rapid descent. The onset of visual disturbances should therefore prompt discontinuation of the possibly offending drug and to consider descending.

Although the effectiveness of acetazolamide in preventing AMS during the very rapid ascent profiles typical on Kilimanjaro is debatable, ${ }^{3}$ we do not suggest that the prophylactic use of acetazolamide during gradual ascents be abandoned on the basis of this report; rather, the possible causes of a problem should be identified and removed if symptoms occur.

\footnotetext{
1. Krieg PH, Schipper I. Drug-induced ciliary body oedema: a new theory. Eye (Lond) 1996:10(1);121-

126.
2. Firth PG, Gray C, Novis CA. High-altitude corneal oedema associated with acetazolamide. S Afr Med J 2011;101(7):462.

3. Jackson SJ, Varley J, Sellers C, et al. Incidence and prevention of mountain sickness among trekkers on Mount Kilimanjaro. High Alt Med Biol 2010;11(3):217-222.
} 